\title{
Caffeine in the management of patients with headache
}

\author{
Richard B. Lipton ${ }^{1 *}$, Hans-Christoph Diener ${ }^{2}$, Matthew S. Robbins ${ }^{1}$, Sandy Yacoub Garas ${ }^{3}$ and Ketu Patel ${ }^{3}$
}

\begin{abstract}
Caffeinated headache medications, either alone or in combination with other treatments, are widely used by patients with headache. Clinicians should be familiar with their use as well as the chemistry, pharmacology, dietary and medical sources, clinical benefits, and potential safety issues of caffeine. In this review, we consider the role of caffeine in the over-the-counter treatment of headache. The MEDLINE and Cochrane databases were searched by combining "caffeine" with the terms "headache," "migraine," and "tension-type." Studies that were not placebocontrolled or that involved medications available only with a prescription, as well as those not assessing patients with migraine and/or tension-type headache (TTH), were excluded. Compared with analgesic medication alone, combinations of caffeine with analgesic medications, including acetaminophen, acetylsalicylic acid, and ibuprofen, showed significantly improved efficacy in the treatment of patients with $\Pi \mathrm{TH}$ or migraine, with favorable tolerability in the vast majority of patients. The most common adverse events were nervousness (6.5\%), nausea (4.3\%), abdominal pain/discomfort (4.1\%), and dizziness (3.2\%). This review provides evidence for the role of caffeine as an analgesic adjuvant in the acute treatment of primary headache with over-the-counter drugs, caffeine doses of $130 \mathrm{mg}$ enhance the efficacy of analgesics in $T \mathrm{TH}$ and doses of $\geq 100 \mathrm{mg}$ enhance benefits in migraine. Additional studies are needed to assess the relationship between caffeine dosing and clinical benefits in patients with TTH and migraine.
\end{abstract}

Keywords: Tension-type headache, Migraine, Caffeine, Acetaminophen, Acetylsalicylic acid, Ibuprofen

\section{Review}

Approximately $11 \%$ of adults worldwide have migraine $[1,2]$, a chronic neurologic disorder characterized by episodic attacks of head pain accompanied by autonomic symptoms as well as sensitivity to light and sounds. Migraine differs from tension-type headache (TTH), a more common condition that is characterized by mild to moderate headache with few or no associated symptoms [3]. Globally, at least $40 \%$ of adults meet criteria for TTH [2]. Both conditions account for substantial rates of absenteeism and lost productivity at work, home, and school, imposing a significant burden on both individuals and society [2].

Most people with migraine or TTH treat their acute headache episodes with medications. Worldwide, more than half of the patients with migraine $(57 \%)$ or TTH

\footnotetext{
* Correspondence: rlipton@aecom.yu.edu

${ }^{1}$ Montefiore Headache Center, Department of Neurology, Albert Einstein

College of Medicine, Louis and Dora Rousso Building, 1165 Morris Park

Avenue, Room 332, Bronx, NY 10461, USA

Full list of author information is available at the end of the article
}

(>80\%) choose over-the-counter (OTC) medications to manage their condition, rather than prescription treatments [4, 5]. For migraine, this treatment approach might be partially explained by the wide spectrum of symptom severity from person-to-person and attack-toattack, ranging from mild pain with little disability to severe pain with complete disability [6]. TTH is typically not associated with debilitating pain or functional impairment [2,3].

In comparison with to OTC medications, prescription drugs are more costly, and are more likely to have more contraindications or undesirable side effects [7-9]. OTC medications can be used without the need for medical consultation [2]. In addition, a number of OTC agents have established efficacy in well-controlled trials in TTH and migraine, including acetaminophen (APAP) [10] and nonsteroidal anti-inflammatory drugs (NSAIDs), such as acetylsalicylic acid (ASA) [11] and ibuprofen (IBU) $[12,13]$. There are also fixed combinations that combine analgesics with caffeine. Two such combinations 
that have demonstrated efficacy for patients with TTH or migraine are APAP $500 \mathrm{mg}$, ASA $500 \mathrm{mg}$, and caffeine $130 \mathrm{mg}$ per 2-tablet dose (AAC-130) and APAP $400 \mathrm{mg}$, ASA $500 \mathrm{mg}$, and caffeine $100 \mathrm{mg}$ per 2-tablet dose (AAC-100). As a result, evidence-based guidelines for the acute treatment of migraine and TTH recognize that OTC drugs are safe and effective treatment options for many patients $[8,14]$. These guidelines also recognize that analgesics combined with caffeine, such as AAC- 130 and AAC-100, have important advantages compared with other widely used OTCs, such as APAP, ASA, and IBU alone.

Caffeinated agents have been in worldwide use by headache patients, either alone or in combination with other treatments, for decades. Clinicians should be familiar with the therapeutic benefits and limitations associated with the use of these agents in clinical practice. Here we review the use of caffeine in primary headache management. We begin by reviewing the sources and consumption of caffeine as well as its chemical properties and pharmacology, clinical use, and safety. Next, we review studies of caffeine in the acute treatment of patients with TTH and migraine.

\section{Caffeine background}

\section{Sources and consumption}

Caffeine is the most widely consumed psychoactive agent in the world [Citation removed]. It occurs naturally in more than 60 plant species, including tea, kola nuts, coffee beans, mate leaves, guarana plants, and cocoa nuts [15]. In humans, the most common sources of caffeine are dietary, as shown in Table 1 [16], although various medications also contain caffeine. Much of the caffeine used commercially is a byproduct of the production of decaffeinated coffee $[17,18]$.

Table 1 Selected sources of dietary and medical caffeine [16]

\begin{tabular}{|c|c|c|c|}
\hline & $\begin{array}{l}\text { Serving size } \\
\text { (oz./mL) }\end{array}$ & & $\begin{array}{l}\text { Caffeine } \\
\text { (mg) }\end{array}$ \\
\hline \multicolumn{4}{|l|}{ Dietary } \\
\hline $\begin{array}{l}\text { FDA limit for cola and pepper } \\
\text { soft drinks }\end{array}$ & 12 & 355 & 71 (200 ppm) \\
\hline Black tea, brewed for 3 min & 8 & 237 & $30-80$ \\
\hline Green tea, brewed for $3 \mathrm{~min}$ & 8 & 237 & $35-60$ \\
\hline \multicolumn{4}{|l|}{ Medical } \\
\hline Midol Complete & 2 caplets & & 120 \\
\hline Bayer Back \& Body & 2 caplets & & 65 \\
\hline Anacin & 2 tablets & & 64 \\
\hline Excedrin ES & 2 tablets & & $130 \mathrm{mg}$ \\
\hline Excedrin Migraine & 2 tablets & & 130 mg \\
\hline Excedrin Tension Headache & 2 tablets & & $130 \mathrm{mg}$ \\
\hline
\end{tabular}

Worldwide, approximately $80 \%$ of adults consume a caffeinated product every day [19], although daily mean consumption rates vary considerably by country. China (16 mg) and Kenya (50 mg) are at the low end of caffeine consumption and Brazil (300 mg) and Denmark (390) are at the high end [15]. In the United States, the vast majority of adults are regular caffeine users (90\%), and estimates of daily consumption range from 168 to $220 \mathrm{mg}$ [15].

\section{Chemistry and pharmacology}

Caffeine, the common name for 1,3,7-trimethylxanthine, is a purine alkaloid with the molecular formula $\mathrm{C}_{8} \mathrm{H}_{10} \mathrm{~N}_{4} \mathrm{O}_{2}$, a molecular weight of $194.1906 \mathrm{~g} / \mathrm{mol}$, and the molecular structure of a trimethyl xanthine (Fig. 1) [18]. Pure caffeine takes the form of white, prismatic crystals; it is odorless, has a slightly bitter taste, and is slightly acidic, with a pH of 6.9 (1\% solution) [18].

Caffeine is completely absorbed by the intestinal tract (ie, its bioavailability is 100\%) [20] and it is highly soluble in water as well as a range of non-polar organic solvents [21]. When administered orally, caffeine takes 30-120 min to reach maximum plasma concentration, although food can slow the absorption process [15]. Caffeine crosses both the blood-brain and placental barriers [22] and it is secreted in human milk, saliva, bile, and semen [21]. About $95 \%$ of a caffeine dose is metabolized in the liver via cytochrome P450 (CYP1A2 demethylation), which converts it into paraxanthine (85\%), theobromine (10\%) and theophylline (5\%) [23, 24]. Less than $2 \%$ of a caffeine dose is eliminated unchanged in urine [23]. In adults, caffeine's elimination half-life is 3$5 \mathrm{~h}$, but it is doubled in smokers and non-coffee drinkers; in newborns, the half-life of caffeine is estimated to be $100 \mathrm{~h}[21,23]$.

The effects of caffeine on nociception are primarily attributed to its nonselective antagonism of the adenosine $A_{1}, A_{2 A}$, and $A_{2 B}$ receptors (as caffeine and adenosine possess a similar molecular structure) and its slightly lower-affinity antagonism for the adenosine $\mathrm{A}_{3}$ receptor

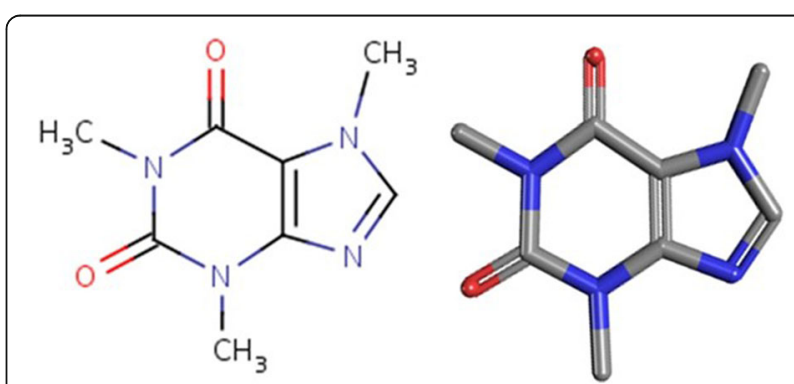

Fig. 1 Molecular structure of caffeine [18]. The molecular structure of caffeine indicates that it is a part of a group of compounds called trimethyl xanthines, which also includes theobromine and theophylline 
$[23,25]$. Through antagonism of the $A_{2 A}$, and $A_{2 B}$ receptors, adenosine induces vasodilation [26, 27]. To combat increased antagonism of these receptors and vasodilation in chronic caffeine users, adenosine receptors are upregulated resulting in vascoconstrictive effects [28]. Additionally, the mechanism by which the adjuvant effects of caffeine occur is not well established although studies have shown that caffeine does not reduce prostaglandin synthesis, a previously suggested mechanism of action [29].

Caffeine dosing influences its pharmacodynamic effects. Higher doses (75-100 $\mathrm{mg} \mathrm{kg}^{-1}$ ) involve central noradrenergic mechanisms, medium to high doses (10$35 \mathrm{mg} \mathrm{kg}^{-1}$ ) activate central amine systems, and low doses $\left(5 \mathrm{mg} \mathrm{kg}^{-1}\right)$ interacting with central cholinergic mechanisms [30]. At therapeutic doses (ie, 100 times those typical in dietary consumption), caffeine can also induce phosphodiesterase inhibition, $\mathrm{Ca}^{2+}$ release, and $\mathrm{GABA}_{\mathrm{A}}$ receptor blockade [23, 30].

\section{Medical applications}

Among patients with headache conditions, caffeine is used as an analgesic adjuvant. Analgesic adjuvants do not relieve pain by themselves, but augment the action of a known analgesic [31]. Factorial studies that examined the effect of analgesics alone, caffeine alone, and the combination of an analgesic and caffeine are required to assess its role as an analgesic adjuvant. In a 1984 meta-analysis of 30 such studies with more than 10,000 patients with postpartum uterine cramping, episiotomy pain, postsurgical pain, or headache, Laska et al., compared AAC-130 with APAP, ASA, and APAP + ASA to assess the therapeutic effect of caffeine as an analgesic adjuvant [32]. The estimated relative potency was 1.41 (95\% CI; 1.23-1.63), indicating that caffeine significantly enhanced the analgesic effect of ASA, APAP, or a combination of the two by about 40\% [32].

There is some evidence that caffeine monotherapy is associated with more pain relief than placebo in treating samples that include either migraine alone or persons with migraine or TTH [33, 34]. There is also limited evidence for the therapeutic use of caffeine monotherapy in patients with other primary and secondary headaches. For example, in patients with post-dural puncture headache (PDPH), studies have shown that acute use of $300 \mathrm{mg}$ (oral) and $500 \mathrm{mg}$ (intravenous) caffeine can provide relief [35]. A Cochrane review concluded that these doses of caffeine were superior to placebo at reducing the proportion of participants with PDPH persistence, as well as those needing supplementary interventions [35]. However, lower doses of caffeine ( $75 \mathrm{mg}$ or $125 \mathrm{mg}$ ) combined with APAP 500 mg given every $6 \mathrm{~h}$ for 3 days have been shown to be ineffective for prophylaxis of PDPH [35], and a review of controlled and open-label studies investigating prophylaxis and treatment of PDPH with oral or IV caffeine cited methodologically weak trials and a paucity of reliable results in concluding that the use of caffeine as an antinociceptive agent for prevention or treatment of patients with PDPH is insufficiently supported by the available pharmacological and clinical evidence [36]. In patients with hypnic headache, an uncommon condition in elderly patients featuring stereotyped attacks of nocturnal headache for which outcomes from controlled studies are lacking, a review of data from observational studies found that the most effective acute treatment is caffeine (given either as 40$60 \mathrm{mg}$ tablets or as a cup of coffee) [37].

When combined with analgesics, caffeine produces a range of clinical effects in these patients. Caffeine promotes the absorption of analgesics, including APAP, ASA, and IBU [38-40]. This effect is attributed to rapid lowering of gastric $\mathrm{pH}$. At low doses $\left(\leq 10 \mathrm{mg} \mathrm{kg}^{-1}\right)$, caffeine has been shown to inhibit the antinociceptive effects of APAP [41], amitriptyline [42], carbamazepine and oxcarbazepine [43]. At higher doses (10-35 mg kg-1), caffeine enhances pain relief with APAP [44, 45] and several different NSAIDs [46, 47]. Meta-analyses of caffeine combined with APAP, ASA, or IBU have found only weak adjuvant effects in patients with postoperative pain $[48,49]$.

Coadministration of caffeine can have other effects that are relevant for patients taking analgesics, including interfering with the effectiveness of some therapies. For instance, a 200-mg caffeine dose can inhibit the analgesic effects of transcutaneous electrical nerve stimulation [50], and consuming caffeine within 2-4 h of intravenous adenosine therapy for paroxysmal supraventricular tachycardia has been shown to necessitate the use of higher adenosine doses [51].

Caffeine has a wide range of physiologic effects that are unrelated to the direct treatment of headache pain but may influence improvement in headache symptoms. Multiple studies have shown that caffeine can enhance mood, alertness [23, 52-55]; exercise performance [56, 57]; the speed at which information is processed, awareness, attention, and reaction time $[58,59]$.

Caffeine also increases gastric motility, as measured by pressure waves and propagated contractions in transverse/ descending colon. The magnitude of the effect of caffeinated coffee is similar to eating a meal, $60 \%$ stronger than water, and $23 \%$ stronger than decaffeinated coffee [60]. Pharmacokinetic studies have shown that the absorption of caffeine is related to gastric emptying [61]. This effect of caffeine has important clinical implications for people with migraines, who may experience reductions in gastric motility both during and between attacks [62]. This reduction in gastric motility slows the absorption of acute medications and reduces their effectiveness [63]. In addition, widely used migraine-specific therapies, including the oral and injectable formulations of sumatriptan, significantly 
decrease gastric motility in healthy volunteers [64-68], potentially exacerbating disease-related gastroparesis and, perhaps, decreasing or delaying oral absorption of triptans resulting in lower efficacy in more advanced attacks of migraine.

\section{Safety}

In the United States, the Food and Drug Administration considers caffeine a substance generally recognized as safe (GRAS) when used in 1) cola-type beverages in accordance with good manufacturing practice and 2) stimulant drug products [69-71]. The caffeine contained in OTC analgesics is limited to a dose of $64-65 \mathrm{mg}$ per tablet though two tablet doses are common [69-72]. In clinical trials, caffeinated analgesics were generally well tolerated and caused the types of mild and transient adverse events (eg, upset stomach) that might be expected from single doses of analgesics at OTC doses [33, 34, 73, 74]. For example, one meta-analysis estimated that adding caffeine to analgesics significantly increased the number of patients who experienced nervousness and dizziness (relative risk 1.60) [75].

Studies also suggest that caffeine stimulates gastric acid production and relaxes the lower esophageal sphincter [76], increasing the risk of gastric and duodenal ulcers $[77,78]$ as well as gastroesophageal reflux disease [79]. However, a meta-analysis of studies enrolling more than 8000 healthy subjects detected no significant association between coffee intake and acid-related upper gastroduodenal ulcer diseases, including gastric and duodenal ulcers, reflux esophagitis, and non-erosive reflux disease [80]. The authors speculated that the known protective effects of coffee (relaxing effect, antioxidant effect, phytochemical effects) might outweigh the risks of increased gastric acid secretion [80].

When used in patients with renal failure, caffeine requires no dose adjustment [12]. However, as a matter of good clinical judgment, it is prudent to consider all analgesics potentially nephrotoxic and to counsel against excessive, protracted use [46, 81]. Excessive use of phenacetin-containing analgesics can cause renal papillary necrosis and interstitial nephritis, but there is no convincing evidence that nonphenacetin-containing analgesics, including acetaminophen (APAP), aspirin (ASA), and mixtures of these two compounds, or NSAIDs, are associated with pathologically or clinically defined renal disease [82].

The role of caffeine in the treatment of migraine is complex. Caffeine combination products are useful in treating migraine and other headache types [33-35]. However, an association between caffeine intake and acute migraines has been observed [83]. Caffeine withdrawal may precipitate headache in the short term (NEJM) while cessation of caffeine may be beneficial. This suggests that complete abstinence of caffeine, like abrupt discontinuation of analgesics for those with $\mathrm{MOH}$ headaches [84], may be beneficial to those suffering from migraines [83]. Furthermore, overuse of APAP/caffeine/ASA has been shown to affect regional brain glucose metabolism in patients with chronic migraine [85].

\section{Potential for overuse}

Frequent use of analgesics is an important health problem [84], and medication overuse by patients with episodic headache conditions is associated with the development of chronic headache conditions [86-89]. Avoiding medication overuse is an important aspect of headache care [3]; once established, medication overuse may be difficult to treat, and recidivism is common [90]. Some research has identified dietary and medicinal caffeine consumption, specifically OTC caffeine combinations, as a modest risk factor for progression from episodic to chronic headache [91, 92]. After adjustment for demographic factors, primary headache type, and number of medications taken, the association of caffeine-containing combinations, and opioid-containing combinations as a risk factor for migraine progression was attenuated [92]. Additional support for the lack of positive association between risk of migraine chronicity and the appropriate use of caffeineanalgesic combinations came from the American Migraine Prevalence and Prevention study, which reported that AAC-130 had no association with development of chronic migraine. After adjusting for headache frequency and medication use, AAC-130 was not associated with an increased risk of chronic migraine onset $(\mathrm{OR}=0.87,95 \% \mathrm{CI}$ $0.64,1.19$ ) [84]. Acute treatment guidelines recommend that in all cases and with all acute medications, migraineurs should limit medication use to 2-3 headache days per week [8] -advice that may apply equally to patients with TTH [93].

Chronic intake of caffeine can cause a dependence syndrome $[94,95]$ that has also been positively associated with a history of cigarette smoking and problematic alcohol use [96]. However, compulsive drug-seeking behavior has never been reported among caffeinedependent persons, and reports of deliberate caffeine abuse are uncommon [97]. It has been suggested that the prevalence of caffeine dependence may increase as a result of the promotion of caffeinated energy drinks to adolescents [98], and cases of intoxication-characterized by nausea/vomiting, tachycardia, hypertension, agitation, and dizziness-have been reported [99]. Caffeinated energy drinks have also been associated with seizures [100], stroke [101], and, rarely, death [102]. These drinks are also frequently combined with alcohol, a combination that has been found to increase alcohol consumption in laboratory animals [103]. Perhaps as a consequence, consumption of alcohol mixed with caffeine 
has been found to be associated with high-risk behaviors such as binge drinking [103].

\section{Tolerance}

Tolerance to the effects of caffeine on blood pressure, heart rate, diuresis, adrenaline and noradrenaline plasma levels, renin activity, and sleep patterns generally occurs within a few days [22], and regular daily doses of 750$1200 \mathrm{mg}$ can lead to tolerance to its subjective, pressor, and neuroendocrine effects [104-106]. In addition, a withdrawal syndrome characterized by headache and sometimes other symptoms (ie, decreased cognitive performance, nausea/vomiting) may occur 12 to $24 \mathrm{~h}$ after stopping chronic consumption of caffeine in about $50 \%$ of patients [22, 31].

Multiple factors, including heritability [107] may contribute to an individual's susceptibility to caffeine withdrawal [108]. The amount of caffeine consumption required to trigger withdrawal varies; while formal diagnostic criteria for caffeine withdrawal headache require daily consumption of $\geq 200 \mathrm{mg}$ for at least 2 weeks [1], symptoms have been observed after sudden termination of caffeine exposures of $300 \mathrm{mg}$ for 3 days and $100 \mathrm{mg}$ for 7 days [109].

Some evidence suggests that caffeine withdrawal may play a role in triggering migraine attacks [110], especially weekend attacks [111]. Data also suggests caffeine withdrawal plays a role in dialysis headaches, a frequent complication of hemodialysis [112]. In addition, postoperative headaches may be partially due to caffeine withdrawal triggered by the abstinence typically required before surgical procedures [113]. Caffeine withdrawal headache can be minimized by a staged reduction and elimination of caffeine intake [97].

\section{Review of randomized trials of OTC analgesics combined with caffeine in the acute treatment of migraine and TTH \\ Methods}

To review literature relating to the use of caffeine by patients with TTH or migraine, research published between January 1966 and November 2016 was retrieved from the MEDLINE and Cochrane databases by combining "caffeine" with each of the following search terms: "headache" (597), "migraine" (365), and "tension-type" (52). Studies that were not placebo-controlled or that involved medications available only with a prescription (eg, butalbital- and ergotamine-caffeine combinations), as well as those not assessing patients with migraine and/or TTH, were excluded. A total of 7 placebocontrolled and factorial trials ( 2 in patients with TTH, 2 in patients with migraine, and 3 in mixed populations) were identified for analysis.

\section{Results}

Efficacy in TTH

In 4 randomized, double-blind, 2-period crossover studies involving 1900 patients with TTH, Migliardi et al. compared AAC-130 with APAP alone and placebo [74]. Efficacy endpoints included pain intensity difference (PID), pain relief (PAR), and total pain relief (TOTPAR). AAC-130 provided significantly greater PID and PAR than APAP alone $(P<.001)$, and both active treatments were superior to placebo $(P<.001)$. As shown in Table 2, the magnitude of the adjuvant effect from caffeine for the summed pain intensity difference (SPID), \%SPID, and TOTPAR was between $76 \%$ and $97 \%$. For measures of peak analgesia and duration of analgesia, the effects were $63-85 \%$ greater than the net analgesic effect of APAP monotherapy [74]. Compared with APAP $1000 \mathrm{mg}$ plus placebo, AAC provided significantly superior total pain relief at 4-h postdose $(P<.001$ vs. APAP and placebo $)[74]$.

Because Migliardi et al. only restricted consumption of dietary caffeine (ie, coffee, tea, soda, chocolate) during the 4-h study period and found significant adjuvancy at the high and low ends of consumption, they concluded that the adjuvant effect was not influenced by patients' usual caffeine consumption. Since the magnitude of caffeine's adjuvant effect was larger for headache than in other forms of pain (ie, episiotomy, postsurgical, etc.) [32], caffeine-containing analgesic combinations may be particularly effective for headache pain [74].

In a randomized, double-blind, parallel-group, multicenter, single-dose, 4-arm, placebo- and active-controlled study, 301 patients with TTH treated a single attack with a 2-tablet dose of IBU $400 \mathrm{mg}+$ caffeine $200 \mathrm{mg}$ (IBC100), IBU $400 \mathrm{mg}$ alone, caffeine $200 \mathrm{mg}$ alone, or placebo [34]. IBC-100 demonstrated significantly shorter times to meaningful improvement in headache relief than IBU alone or placebo; significantly greater total analgesia than IBU alone, caffeine alone, or placebo; and significantly greater peak relief than IBU alone, caffeine alone, or placebo $(P<.05)$. Significantly more subjects obtained meaningful headache relief with IBC-100 than with IBU alone or placebo $(P<.05)$. IBC-100 provided greater analgesic effectiveness than either component alone [51].

\section{Efficacy in migraine}

The efficacy of AAC-130 in migraine was established by Lipton et al. in 3 double-blind, placebo-controlled, parallel-group studies that randomized a total of 1220 migraineurs, excluding subjects who vomited more than $20 \%$ of the time or who usually required bed rest [73]. At 2 -h postdose, pain-free rates were $21 \%$ for AAC- 130 and $7 \%$ for placebo, and headache response (pain reduced from moderate or severe to mild or none) was $59 \%$ for AAC-130 and 33\% for placebo. At 6-h postdose, 
Table 2 Pooled results from 2 TTH trials in patients over $4 \mathrm{~h}$ for AAC-130, APAP, and placebo [74]

\begin{tabular}{llll}
\hline Measure & AAC-130 $(n=1369)$ & APAP $(n=1376)$ & Placebo $(n=689)$ \\
\hline SPID & $5.30 \pm 0.06^{\mathrm{a}, \mathrm{b}}$ & $4.70 \pm 0.07^{\mathrm{b}}$ & $3.95 \pm 0.10$ \\
\%SPID & $57.6 \pm 0.7^{\mathrm{a}, \mathrm{b}}$ & $50.6 \pm 0.7^{\mathrm{b}}$ & $42.7 \pm 1.0$ \\
Maximum PID & $1.89 \pm 0.02^{\mathrm{a}, \mathrm{b}}$ & $1.74 \pm 0.02^{\mathrm{b}}$ & $1.53 \pm 0.03$ \\
TOTPAR & $10.52 \pm 0.10^{\mathrm{a}, \mathrm{b}}$ & $9.38 \pm 0.10^{\mathrm{b}}$ & $8.20 \pm 0.16$ \\
Maximum PAR & $3.42 \pm 0.02^{\mathrm{a}, \mathrm{b}}$ & $3.14 \pm 0.03^{\mathrm{b}}$ & $2.81 \pm 0.04$ \\
Time to pain at least half gone (hours) & $3.01 \pm 0.03^{\mathrm{a}, \mathrm{b}}$ & $2.73 \pm 0.03^{\mathrm{b}}$ & $2.38 \pm 0.05$ \\
\hline
\end{tabular}

AAC-130, acetaminophen $500 \mathrm{mg}$, aspirin $500 \mathrm{mg}$, and caffeine $130 \mathrm{mg}$ per 2-tablet dose; APAP, acetaminophen $1000 \mathrm{mg}$ per 2-tablet dose; SPID, sum of pain intensity differences; PID, pain intensity difference from baseline; TOTAR, total pain relief; PAR, pain relief

Values are mean \pm standard error

${ }^{\text {a }} P<0.05$ vs APAP

${ }^{\mathrm{b}} P<0.05$ vs placebo

$51 \%$ of patients treated with AAC-130 were pain-free compared with $24 \%$ of placebo-treated patients, and $79 \%$ of patients treated with AAC had a headache response versus $52 \%$ of those treated with placebo $(P<.001$ for all comparisons). The significant advantages of AAC-130 over placebo were also seen at 2- and 6-h postdose for relief of pain, associated symptoms, and disability (Table 3 ) [73]. Vomiting was less frequent in those treated with AAC-130 (0.2\%) than placebo-treated patients $(1.6 \%$; $P=.01$ ) [73]. Although this study confirmed that a fixed combination containing caffeine could effectively treat a select population of migraineurs, the adjuvant effect of caffeine could not be assessed because a factorial design was not used.

Table 3 Pooled results from 3 migraine trials: AAC-130 versus placebo for migraine at 2 and $6 \mathrm{~h}$ postdose [73]

\begin{tabular}{lll}
\hline & $\begin{array}{l}\text { AAC-130 } \\
n=602\end{array}$ & $\begin{array}{l}\text { Placebo } \\
n=618\end{array}$ \\
\hline Results at 2 hours & & \\
PID & $1.0^{\mathrm{b}}$ & 0.4 \\
Proportion pain-free (\%) & $21^{\mathrm{b}}$ & 7 \\
Proportion nausea-free (\%) & $63^{\mathrm{c}}$ & 56 \\
Proportion photophobia-free (\%) & $35^{\mathrm{b}}$ & 17 \\
Proportion phonophobia-free (\%) & $37^{\mathrm{b}}$ & 19 \\
Proportion with little or no & $59^{\mathrm{b}}$ & 34 \\
functional disability (\%) & & \\
Results at 6 h & $1.4^{\mathrm{b}}$ & 0.6 \\
PID & $51^{\mathrm{b}}$ & 23 \\
Proportion pain-free (\%) & $74^{\mathrm{b}}$ & 60 \\
Without nausea (\%) & $58^{\mathrm{b}}$ & 31 \\
Without photophobia (\%) & $59^{\mathrm{b}}$ & 33 \\
Without phonophobia (\%) & $69^{\mathrm{b}}$ & 41 \\
\hline Little or no functional disability (\%)
\end{tabular}

AAC-130, acetaminophen $500 \mathrm{mg}$, aspirin $500 \mathrm{mg}$, caffeine $130 \mathrm{mg}$ per 2-tablet dose; PID, pain intensity difference from baseline

${ }^{\mathrm{a}}$ Rescue medication was permitted at $2 \mathrm{~h}$ postdose

${ }^{\mathrm{b}} P<0.001$ versus placebo

${ }^{c} P<0.01$ versus placebo
In a 3-arm, double-blind, parallel group study of migraine, Goldstein and coworkers (2006) treated 1555 patients with a fixed combination of AAC (acetaminophen $500 \mathrm{mg}$, acetylsalicylic acid $500 \mathrm{mg}$, and caffeine $130 \mathrm{mg}$ ), IBU $400 \mathrm{mg}$ or placebo. In comparison with placebo-treated participants, both active treatment arms demonstrated better relief of pain and associated symptoms. AAC was superior to IBU for a number of endpoints, including TOTPAR at $2 \mathrm{~h}$, time to onset of meaningful PAR, pain intensity reduction, headache response, and pain free. The mean TOTPAR2 scores were 2.7 for AAC, 2.4 for IBU, and 2.0 for placebo (AAC vs IBU, $P<0.03)$. The median time to meaningful PAR for AAC was 20 min earlier than that of IBU $(P<0.036)$. The influence of caffeine once again could not be assessed as this was not a factorial study [114].

\section{Efficacy in mixed populations (TTH and migraine)}

Two studies evaluated the efficacy of analgesics and caffeine in study populations that included patients with TTH and migraine [33, 115]. In the first, Diener et al. studied AAC-100 (APAP $200 \mathrm{mg}$, ASA $250 \mathrm{mg}$, and caffeine $50 \mathrm{mg}$ ), which is available OTC in Germany, in patients with TTH and migraine using a 6-arm, randomized, double-blind, parallel-group factorial design. The fixed combination AAC-100 was compared with APAP $200 \mathrm{mg}$ and ASA $250 \mathrm{mg}$, APAP alone, ASA alone, caffeine alone and with placebo in 1743 subjects who typically treated their headaches with OTC medications [33]. Pain intensity was recorded on a 100-mm visual analogue scale. Among enrolled subjects, $84 \%$ had migraine, $13 \%$ had episodic $\mathrm{TTH}$, and $3 \%$ could not be classified. The primary endpoint was time to $50 \%$ pain relief (PAR).

Time to 50\% PAR, AAC-100 was significantly better than the APAP $200 \mathrm{mg}$-ASA $250 \mathrm{mg}$ combination $(P=.02)$, ASA $250 \mathrm{mg}(P=.04)$, APAP $200 \mathrm{mg}(P=.002)$, caffeine $50 \mathrm{mg}(P<.0001)$, and placebo $(P<.0001)$. All active treatments, except caffeine $50 \mathrm{mg}$, were significantly superior to PLA $(P<.0001)[33]$. The median time to $50 \%$ PAR was $65 \mathrm{~min}$ with AAC-100, $73 \mathrm{~min}$ with APAP 
$200 \mathrm{mg}$-ASA $250 \mathrm{mg}, 79 \mathrm{~min}$ with ASA $250 \mathrm{mg}, 81 \mathrm{~min}$ with APAP $200 \mathrm{mg}, 107 \mathrm{~min}$ with caffeine $50 \mathrm{mg}$, and 133 min with placebo. Additional efficacy results comparing AAC-100 with the analgesic combination without caffeine and its constituents are shown in Table 4 [33]. It was concluded that AAC-100 significantly outperformed all the other treatments for reductions in pain intensity, and that the clinically meaningful improvements compared with APAP or ASA monotherapy confirmed the existence of an adjuvant effect of caffeine in migraineurs. Diener et al. also pointed out that, because their patient population typically treated their headache attacks with OTCs, findings can be generalized to the larger population of migraineurs and patients with TTH [33].

\section{Efficacy in children and adolescents with migraine or TTH}

A double-blind, crossover pilot study comparing the efficacy of an IBU-caffeine combination with an IBU-placebo combination in 12 children ( 7 girls, 5 boys) aged 7 to 15 years $($ mean $=11.9$ years) who had TTH $(25 \%)$ or migraine (75\%) was conducted [116]. Study treatments, adjusted to subjects' weight, included $100 \mathrm{mg}$ IBU $+50 \mathrm{mg}$ caffeine; $200 \mathrm{mg}$ IBU $+50 \mathrm{mg}$ caffeine; $300 \mathrm{mg}$ $\mathrm{IBU}+100 \mathrm{mg}$ caffeine; or $400 \mathrm{mg} \mathrm{IBU}+100 \mathrm{mg}$ of caffeine. Baseline pain intensity, which was assessed on a 4-point scale $(4=$ severe, $3=$ moderate, $2=$ mild, $1=$ no pain), was 3.8 in the IBU-caffeine treatment group and 4.0 in the IBU-placebo group [116].

A total of $58 \%$ of children obtained faster relief with the IBU-caffeine combination, while $33 \%$ appeared to achieve earlier relief with IBU and placebo, and $8 \%$ exhibited no difference in the response [116]. Time to meaningful relief (pain intensity $\leq 2$ ) was about twice as fast $(60 \mathrm{~min}$ ) for attacks treated with IBU-caffeine as it was for those treated with IBU-placebo $(\approx 120 \mathrm{~min})$. At $30 \mathrm{~min}$ postdose, PID in the IBU-caffeine group was 1.0 compared with 0.2 in the IBU-placebo group; at $60 \mathrm{~min}$ postdose, PID scores were 1.5 for IBU-caffeine and 0.9 for IBU-placebo. Although the IBU-caffeine combination failed to separate significantly on any efficacy endpoint in this small pilot study, it was numerically superior to the IBU-placebo combination, and almost $60 \%$ of patients realized clinically important benefits [116].

\section{Tolerability}

In these studies, $\geq 96 \%$ of patients reported adverse events (AEs) $[33,34,73,74]$. AEs were usually mild or moderate, and no subject in any study withdrew as a result of an $\mathrm{AE}$ that was considered to be related to active treatment. Across all studies and patient types, the most commonly reported treatment-emergent AEs were nervousness $(6.5 \%$ [4.0-11.0\%]), nausea (4.3\% [1.0-7.0\%]), abdominal pain/ discomfort (4.1\% [1.1-9.0\%]), and dizziness (3.2\% [0.8$6.0 \%])[33,34,73,74]$.

\section{Estimate of benefit}

Previous meta-analyses have estimated that combining analgesics and/or NSAIDs with caffeine improves antinociception. In patients with a range of pain conditions, Laska et al. suggested an adjuvant effect of 1.42 for AAC-130 compared with APAP or ASA monotherapy [32]. Migliardi et al. estimated an adjuvant benefit of 1.63-1.97 for AAC-130 versus APAP in patients with TTH [74]. Zhang found an effect of 1.36 (95\% CIs 1.171.58) for APAP-caffeine combinations versus APAP alone in patients with headache [75]. A Cochrane review of caffeine adjuvancy in various pain states reported that the number needed to treat (NNT) for an additional patient

Table 4 Results of a 6-arm factorials study of the acute treatment of migraine and TTH ${ }^{\mathrm{a}}$ [33]

\begin{tabular}{|c|c|c|c|c|c|c|}
\hline Measure & AAC-100 & APAP + ASA & APAP & ASA & Caffeine & Placebo \\
\hline PID @ 2 h (mm) & 44.7 & 40.2 & 39.5 & 40.7 & 31.4 & 24.6 \\
\hline Active vs placebo & $<0.0001$ & $<0.0001$ & $<0.0001$ & $<0.0001$ & $<0.02$ & - \\
\hline Active vs AAC-100 & - & 0.002 & 0.02 & 0.003 & $<0.0001$ & $<0.0001$ \\
\hline Weighted SPID (\%) & 66.6 & 62.0 & 57.5 & 62.2 & 46.7 & 40.2 \\
\hline P vs placebo & $<0.0001$ & $<0.0001$ & $<0.0001$ & $<0.0001$ & 0.0993 & - \\
\hline$P$ vs $A A C-100$ & - & 0.02 & 0.07 & 0.0002 & $<0.0001$ & $<0.0001$ \\
\hline Functional disability @ 2 h (\%) & 53.9 & 49.4 & 48.6 & 48.4 & 39.4 & 30.5 \\
\hline P vs placebo & $<0.0001$ & $<0.0001$ & $<0.0001$ & $<0.0001$ & 0.1491 & - \\
\hline$P$ vs AAC-100 & - & 0.08 & 0.08 & 0.04 & $<0.0001$ & $<0.0001$ \\
\hline Global assessment of efficacy (\%) & 25.2 & 21.4 & 15.4 & 18.7 & 20.8 & 10.9 \\
\hline P vs placebo & $<0.0001$ & $<0.0001$ & $<0.0001$ & $<0.0001$ & 0.0132 & - \\
\hline$P$ vs AAC -100 & - & 0.01 & $<0.0001$ & 0.009 & $<0.0001$ & $<0.0001$ \\
\hline
\end{tabular}

AAC-100, acetaminophen 400 mg, aspirin 500 mg, caffeine $100 \mathrm{mg}$ per 2-tablet dose; APAP + ASA, acetaminophen $400+$ aspirin 500 mg per 2-tablet dose; APAP, acetaminophen $400 \mathrm{mg}$ per 2-tablet dose; ASA, aspirin $500 \mathrm{mg}$ per 2-tablet dose; caffeine, caffeine $100 \mathrm{mg}$ per 2-tablet dose; PID, pain intensity difference from baseline; SPID, sum of pain intensity differences

${ }^{\mathrm{a}}$ The study population included patients with migraine $(84 \%)$ and $\mathrm{TH}(13 \%)$ who typically treated attacks with non-prescription analgesics 
to have relief of headache pain was 14 while the NNTs for postoperative dental pain, postoperative pain, and dysmenorrhea pain were 13,16 , and 25 , respectively. Considered by dose, $65 \mathrm{mg}$ or less had no adjuvant effect in postoperative pain, while the NNT for doses of 70$150 \mathrm{mg}$ was 14, and for doses above $150 \mathrm{mg}$, the NNT was $10 .{ }^{164}$ Overall, there appeared to be a small but clinically significant benefit to adding caffeine to analgesic therapy for various types of acute pain, but more research is needed to optimize dosing recommendations [117].

\section{Discussion}

This review provides evidence for the role of caffeine as an analgesic adjuvant in the acute treatment of primary headache with OTC drugs. A dose of $130 \mathrm{mg}$ enhances the efficacy of OTC analgesics in TTH and a dose of $\geq 100 \mathrm{mg}$ enhances the benefits of OTC analgesics in migraine. The incidence of treatment-emergent AEs in these studies was low, and the type and severity of AEs was similar across headache diagnoses. It seems likely that abdominal pain was probably due to the presence of NSAIDs (ie, ASA or IBU), while nervousness, nausea, and dizziness were most likely related to consumption of caffeine. These AEs, none of which were severe or unexpected, suggest that most patients who use caffeine-containing OTC combinations for occasional, acute treatment of TTH or migraine will experience good tolerability with appropriate use.

The relationship between caffeine and headache is complex, paradoxical, and often misunderstood. Used appropriately, caffeine significantly enhances the effectiveness of analgesics and NSAIDs in the treatment of patients with migraine and TTH. Used to excess, caffeine-containing analgesics can place patients at risk of medication overuse headache $(\mathrm{MOH})$ and the progressive development of chronic TTH or chronic migraine [1]. At the same time, results from an uncontrolled, clinic-based study suggest that discontinuing caffeine consumption can improve the efficacy of acute migraine treatment [83].

Caffeine also has intrinsic antinociceptive properties, which enable it to be used as a monotherapy for relief of hypnic headache. However, large acute doses can precipitate headache, as can abrupt cessation after regular dietary consumption. On the other hand, if addition of caffeine improves efficacy, it may reduce the number of doses of acute medication need to successfully treat an attack of migraine. In addition, patients are often willing to use OTC products earlier in an attack of headache which likely improves outcome and may reduce need for further treatment. The risk of $\mathrm{MOH}$ is one of frequency of use.

Appropriate dosing of caffeine in patients with migraine or TTH remains uncertain. Laska et al. suggest that a caffeine dose of $130 \mathrm{mg}$ may be optimal for achieving the analgesic adjuvant effect among patients with headache [32], as lower doses $(<60 \mathrm{mg})$ generally do not show a reliable adjuvant effect. Further, if low doses of caffeine inhibit antinociception, dietary caffeine might interfere with analgesic efficacy [31].

Awareness of the role of caffeine in the management of patients with headache should facilitate optimal use and help to avoid or address MOH. In clinical practice, certain groups of patients may benefit, including those with a partial response to simple analgesics and migraineurs with prominent gastroparesis-related nausea.

\section{Conclusions}

Caffeine is widely consumed around the world in both food and beverages, and it has a variety of important medical applications. In patients with headache disorders, caffeine monotherapy may be useful in some forms of primary or secondary headache. Its principal role is as an adjuvant in fixed combinations with analgesic medications for acute treatment of TTH and migraine. Evidence from clinical trials in these patient populations indicates that combining caffeine with OTC analgesic medications, such as APAP, ASA, and IBU, significantly improves efficacy over the analgesic alone. As might be expected with OTC preparations, tolerability is good for the vast majority of patients, and AEs are predictable and almost universally mild and transient. Additional studies are needed to assess the relationship between caffeine dosing and clinical benefit in patients with TTH and migraine.

\section{Abbreviations \\ AAC-100: APAP 400 mg, ASA 500 mg, and caffeine 100 mg; AAC-130: APAP \\ $500 \mathrm{mg}$, ASA $500 \mathrm{mg}$, and caffeine $130 \mathrm{mg}$; AE: Adverse event; \\ APAP: Acetaminophen; ASA: Acetylsalicylic acid; GRAS: Generally recognized \\ as safe; IBC-100: IBU $400 \mathrm{mg}$ and caffeine $200 \mathrm{mg}$; IBU: Ibuprofen; \\ MOH: Medication overuse headache; NNT: Number needed to treat; \\ NSAID: Nonsteroidal anti-inflammatory drugs; OTC: Over the counter; PAR: Pain relief; PDPH: Post-dural puncture headache; PID: Pain intensity difference; SPID: Summed pain intensity difference; TOTPAR: Total pain relief; TTH: Tension-type headache}

\section{Authors' contributions}

RBL was involved in drafting the manuscript or revising it critically for important intellectual content, gave final approval of the version to be published, and agreed to be accountable for all aspects of the work in ensuring that questions related to the accuracy or integrity of any part of the work are appropriately investigated and resolved. H-CD was involved in drafting the manuscript or revising it critically for important intellectual content, gave final approval of the version to be published, and agreed to be accountable for all aspects of the work in ensuring that questions related to the accuracy or integrity of any part of the work are appropriately investigated and resolved. MSR was involved in drafting the manuscript or revising it critically for important intellectual content, gave final approval of the version to be published, and agreed to be accountable for all aspects of the work in ensuring that questions related to the accuracy or integrity of any part of the work are appropriately investigated and resolved. SYG was involved in drafting the manuscript or revising it critically for important intellectual content, gave final approval of the version to be published, and agreed to be accountable for all aspects of the work in ensuring that questions related to the accuracy or integrity of any part of the work are appropriately investigated and resolved. KP was involved in drafting the manuscript or revising it critically for important intellectual content, gave final approval of the version to be published, and agreed to 
be accountable for all aspects of the work in ensuring that questions related to the accuracy or integrity of any part of the work are appropriately investigated and resolved. All authors read and approved the final manuscript

\section{Competing interests}

Richard B. Lipton has received personal fees from Alder, Allergan, Amgen, Electrocore, eNeura, Boston Scientific, Bristol Meyers Squibb, Dr. Reddys, Eli Lilly, Teva, Vedanta. He has also received grant funding from Alder, Electrocore, Novartis, the Migraine Research Fund, the National Headache Foundation, and the National Institute of Health. Dr. Lipton owns stock in eNeura and Biohaven.

Hans-Christoph Diener has received honoraria from Addex Pharma, Adler, Allergan, Almirall, Amgen, Autonomic Technologies, AstraZeneca, Bayer Vital, Berlin Chemie, Boehringer Ingelheim, Bristol-Myers Squibb, Chordate Medical, Coherex Medical, CoLucid Pharmaceuticals, Electrocore, GlaxoSmithKline, Grunenthal, Janssen-Cilag, Labrys Biologicals, Eli Lilly, La Roche, 3 M Medica, Medtronic, Menarini, Minster Pharmaceuticals, MSD, NeuroScore, Novartis, Johnson \& Johnson, Pierre Fabre, Schaper and Brummer, St. Jude Medical Foundation, Weber \& Weber, and Pfizer. He has received research funding from Allergan, Almirall, AstraZeneca, Bayer, Electrocore, GlaskoSmithKline, Janssen-Cilag, MSD, Pfizer, the German Science Council, the German Secretary of Education, the European Union, and Teva.

Matthew S. Robbins has received honoraria for educational activities from the American Headache Society, American Academy of Neurology, Medlink, and Springer and has received book royalties from Wiley. He has participated as a site principal investigator for a clinical trial sponsored by eNeura, Inc. with funds sent directly to his institution.

Sandy Yacoub Garas is a salaried employee of GlaxoSmithKline Consumer Healthcare.

Ketu Patel is a salaried employee of GlaxoSmithKline Consumer Healthcare.

\section{Publisher's Note}

Springer Nature remains neutral with regard to jurisdictional claims in published maps and institutional affiliations.

\section{Author details}

${ }^{1}$ Montefiore Headache Center, Department of Neurology, Albert Einstein College of Medicine, Louis and Dora Rousso Building, 1165 Morris Park Avenue, Room 332, Bronx, NY 10461, USA. ²Department of Neurology, University Duisburg-Essen, Essen, Germany. ${ }^{3}$ GlaxoSmithKline Consumer Healthcare, Parsippany, NJ, USA.

\section{Received: 15 June 2017 Accepted: 8 September 2017} Published online: 24 October 2017

\section{References}

1. The International Classification of Headache Disorders (2013) 3rd Edition (beta version). Cephalalgia 33(9):629-808

2. Stovner $L$ et al (2007) The global burden of headache: a documentation of headache prevalence and disability worldwide. Cephalalgia 27(3):193-210

3. Loder E, Rizzoli P (2008) Tension-type headache. BMJ 336(7635):88-92

4. P, M., Socioeconomic costs of headache, in The headaches, O. J, T.-H. P, and W. KMA, Editors. 2000, Lippencott Williams \& Wilkins: Philadelphia. p. 33-40

5. Rasmussen BK (2001) Epidemiology of headache. Cephalalgia 21(7):774-777

6. Lipton RB, Newman LC, Solomon S (1994) Over-the-counter medication and the treatment of migraine. Headache 34(9):547-548

7. J, S. and W. W, Tension-type headache, in Headache, G. PJ and S. SD, Editors. 1997, Butterworth-Heinemann: Boston. p. 177-200

8. Silberstein, S.D., Practice parameter: evidence-based guidelines for migraine headache (an evidence-based review): report of the quality standards Subcommittee of the American Academy of neurology. Neurology, 2000. 55(6): p. 754-762

9. Silberstein SD (2004) Migraine. Lancet 363(9406):381-391

10. Prior MJ, Codispoti JR, Fu M (2010) A randomized, placebo-controlled trial of acetaminophen for treatment of migraine headache. Headache 50(5):819-833

11. Lipton RB et al (2005) Aspirin is efficacious for the treatment of acute migraine. Headache 45(4):283-292

12. Codispoti JR et al (2001) Efficacy of nonprescription doses of ibuprofen for treating migraine headache. A randomized controlled trial. Headache 41(7):665-679
13. Kellstein DE et al (2000) Evaluation of a novel solubilized formulation of ibuprofen in the treatment of migraine headache: a randomized, doubleblind, placebo-controlled, dose-ranging study. Cephalalgia 20(4):233-243

14. G, H., et al., Self-medication in migraines and tension headache: evidencebased recommendations of German Migraine and Headache Association (DMKG), German Neurological Society (DGN), the Autrian Headache Association (OKSG) and the Swiss Headache Association (SKG). Nervenheilkunde, 2009. 6: p. 382-397

15. Frary CD, Johnson RK, Wang MQ (2005) Food sources and intakes of caffeine in the diets of persons in the United States. J Am Diet Assoc 105(1):110-113

16. Interest, C.f.S.i.t.P., Caffeine content of food and drugs. Available awww. cspinet.org/new/cafchart.htm. Accessed Nov 2014

17. RJ, L., Hawley's Condensed chemical dictionary. 14 ed. 2001, New York: John Wiley \& Sons

18. PubChem, Caffeine (2015) Available at: http://pubchem.ncbi.n/m.nih.gov/ summary/summary.cgi?q=all\&cid=2519\#. Accessed Nov 2014

19. Ogawa N, Ueki H (2007) Clinical importance of caffeine dependence and abuse. Psychiatry Clin Neurosci 61(3):263-268

20. Blanchard J, Sawers SJ (1983) The absolute bioavailability of caffeine in man. Eur J Clin Pharmacol 24(1):93-98

21. Sawynok J, Yaksh TL (1993) Caffeine as an analgesic adjuvant: a review of pharmacology and mechanisms of action. Pharmacol Rev 45(1):43-85

22. Juliano LM, Griffiths RR (2004) A critical review of caffeine withdrawal: empirical validation of symptoms and signs, incidence, severity, and associated features. Psychopharmacology 176(1):1-29

23. Fredholm BB et al (1999) Actions of caffeine in the brain with special reference to factors that contribute to its widespread use. Pharmacol Rev 51(1):83-133

24. Safranow K, Machoy Z (2005) Methylated purines in urinary stones. Clin Chem 51(8):1493-1498

25. J, S., Adenosine and ATP receptors, in Handbook of experimental pharmacology, S. C, Editor. 2006, Springer: Berlin. p. 301-320

26. Coney AM, Marshall JM (1998) Role of adenosine and its receptors in the vasodilatation induced in the cerebral cortex of the rat by systemic hypoxia. J Physiol 509(Pt 2):507-518

27. Ngai AC et al (2001) Receptor subtypes mediating adenosine-induced dilation of cerebral arterioles. Am J Physiol Heart Circ Physiol 280(5):H2329

28. Addicott MA et al (2009) The effect of daily caffeine use on cerebral blood flow: how much caffeine can we tolerate? Hum Brain Mapp 30(10):3102-3114

29. Fernández-Dueñas $\vee$ et al (2008) Adjuvant effect of caffeine on acetylsalicylic acid anti-nociception: prostaglandin E2 synthesis determination in carrageenan-induced peripheral inflammation in rat. Eur J Pain 12(2):157-163

30. Sawynok J (2011) Methylxanthines and pain. Handb Exp Pharmacol 200: 311-329

31. Sawynok J (2011) Caffeine and pain. Pain 152(4):726-729

32. Laska EM et al (1984) Caffeine as an analgesic adjuvant. JAMA 251(13): $1711-1718$

33. Diener $\mathrm{HC}$ et al (2005) The fixed combination of acetylsalicylic acid, paracetamol and caffeine is more effective than single substances and dual combination for the treatment of headache: a multicentre, randomized, double-blind, single-dose, placebo-controlled parallel group study. Cephalalgia 25(10):776-787

34. Diamond S, Balm TK, Freitag FG (2000) Ibuprofen plus caffeine in the treatment of tension-type headache. Clin Pharmacol Ther 68(3):312-319

35. Basurto, O., X, et al., Drug therapy for treating post-dural puncture headache. Cochrane. Database. Syst. Rev, 2011 (8): p. CD007887

36. Halker RB et al (2007) Caffeine for the prevention and treatment of postdural puncture headache: debunking the myth. Neurologist 13(5):323-327

37. Liang JF, Wang SJ (2014) Hypnic headache: a review of clinical features, therapeutic options and outcomes. Cephalalgia 34(10):795-805

38. PB B., et al., The effect of caffeine on ibuprofen pharmacokinetics. Acta Pharmacol Toxicol, 1986. 59: p. 54

39. Price VF, Gale GR (1987) Effects of caffeine on biotransformation and elimination kinetics of acetaminophen in mice. Res Commun Chem Pathol Pharmacol 57(2):249-260

40. Yoovathaworn KC, Sriwatanakul K, Thithapandha A (1986) Influence of caffeine on aspirin pharmacokinetics. Eur J Drug Metab Pharmacokinet 11(1):71-76 
41. Godfrey L et al (2006) Modulation of paracetamol antinociception by caffeine and by selective adenosine A2 receptor antagonists in mice. Eur J Pharmacol 531(1-3):80-86

42. Sawynok J, Reid AR, Fredholm BB (2008) Caffeine reverses antinociception by amitriptyline in wild type mice but not in those lacking adenosine A1 receptors. Neurosci Lett 440(2):181-184

43. Tomic MA et al (2004) The anti-hyperalgesic effects of carbamazepine and oxcarbazepine are attenuated by treatment with adenosine receptor antagonists. Pain 111(3):253-260

44. Gayawali K, Pandhi P, Sharma PL (1991) Determination of the optimal analgesiapotentiating dose of caffeine and a study of its effect on the pharmacokinetics of aspirin in mice. Methods Find Exp Clin Pharmacol 13(8):529-533

45. Granados-Soto $V$ et al (1993) Characterization of the analgesic effect of paracetamol and caffeine combinations in the pain-induced functional impairment model in the rat. J Pharm Pharmacol 45(7):627-631

46. Delzell E, Shapiro S (1998) A review of epidemiologic studies of nonnarcotic analgesics and chronic renal disease. Medicine (Baltimore) 77(2):102-121

47. Lopez JR et al (2006) Enhancement of antinociception by co-administration of ibuprofen and caffeine in arthritic rats. Eur J Pharmacol 544(1-3):31-38

48. Po AL, Zhang WY (1998) Analgesic efficacy of ibuprofen alone and in combination with codeine or caffeine in post-surgical pain: a meta-analysis. Eur J Clin Pharmacol 53(5):303-311

49. Zhang WY, Po AL (1997) Do codeine and caffeine enhance the analgesic effect of aspirin?-a systematic overview. J Clin Pharm Ther 22(2):79-97

50. Marchand S, Li J, Charest J (1995) Effects of caffeine on analgesia from transcutaneous electrical nerve stimulation. N Engl J Med 333(5):325-326

51. Cabalag MS et al (2010) Recent caffeine ingestion reduces adenosine efficacy in the treatment of paroxysmal supraventricular tachycardia. Acad Emerg Med 17(1):44-49

52. Horne JA, Reyner LA (1996) Counteracting driver sleepiness: effects of napping, caffeine, and placebo. Psychophysiology 33(3):306-309

53. Kaplan GB et al (1997) Dose-dependent pharmacokinetics and psychomotor effects of caffeine in humans. J Clin Pharmacol 37(8):693-703

54. Lorist MM, Tops M (2003) Caffeine, fatigue, and cognition. Brain Cogn 53(1):82-94

55. Silverman K, Mumford GK, Griffiths RR (1994) Enhancing caffeine reinforcement by behavioral requirements following drug ingestion. Psychopharmacology 114(3):424-432

56. Doherty M, Smith PM (2004) Effects of caffeine ingestion on exercise testing: a meta-analysis. Int J Sport Nutr Exerc Metab 14(6):626-646

57. Ganio MS et al (2009) Effect of caffeine on sport-specific endurance performance: a systematic review. J Strength Cond Res 23(1):315-324

58. Cysneiros RM et al (2007) Pharmacokinetic and pharmacodynamic interactions between zolpidem and caffeine. Clin Pharmacol Ther 82(1):54-62

59. Mitchell PJ, Redman JR (1992) Effects of caffeine, time of day and user history on study-related performance. Psychopharmacology 109(1-2):121-126

60. Klatsky AL, Armstrong MA, Friedman GD (1993) Coffee, tea, and mortality. Ann Epidemiol 3(4):375-381

61. Higaki K et al (2008) Mechanistic understanding of time-dependent oral absorption based on gastric motor activity in humans. Eur J Pharm Biopharm 70(1):313-325

62. Aurora SK et al (2006) Gastric stasis in migraine: more than just a paroxysmal abnormality during a migraine attack. Headache 46(1):57-63

63. Silberstein S (2013) Gastrointestinal manifestations of migraine: meeting the treatment challenges. Headache 53(Suppl 1):1-3

64. Houghton LA et al (1992) Effect of sumatriptan, a new selective 5HT1-like agonist, on liquid gastric emptying in man. Aliment Pharmacol Ther 6(6):685-691

65. Malatesta MG et al (2002) 5-HT1-Receptor agonist sumatriptan modifies gastric size after $500 \mathrm{ml}$ of water in dyspeptic patients and normal subjects. Dig Dis Sci 47(11):2591-2595

66. Sakamoto $Y$ et al (2012) Effect of sumatriptan on gastric emptying: a crossover study using the BreathID system. World J Gastroenterol 18(26):3415-3419

67. Tack J et al (1998) Role of impaired gastric accommodation to a meal in functional dyspepsia. Gastroenterology 115(6):1346-1352

68. Vingerhagen $\mathrm{S}$ et al (2000) Influence of a $5 \mathrm{HT} 1$ receptor agonist on gastric accommodation and initial transpyloric flow in healthy subjects. Neurogastroenterol Motil 12(1):95-101

69. U.S. National Archives and Records Administration's Electronic Code of Federal Regulations. 21 CFR 182.1180. Available at https://www.gpo.gov/ fdsys/granule/CFR-2011-title21-vol3/CFR-2011-title21-vol3-sec182-1180/ content-detail.html. Accessed 22 Sept 2017
70. U.S. National Archives and Records Administration's Electronic Code of Federal Regulations. 21 CFR 340.10. Available at https:/www.accessdata.fda.gov/ scripts/cdrh/cfdocs/cfcfr/CFRSearch.cfm?fr=340.10. Accessed 22 Sept 2017

71. U.S. National Archives and Records Administration's Electronic Code of Federal Regulations. 21 CFR 310.545. Available at http://www/ecfr/gpv/cgibin/text-idx?c=ecfr\&tpl=/ecfbrowse/Title21/21cfr310_main_02.tpl. Accessed Nov 2014

72. Administration, U.F.a.D., Cover letter, Docket No. 77N-0094. https://www.fda. gov/ohrms/dockets/dockets/77n0094/77n-0094-cp00015_05_Safety_ Assessment_Supporting_Caffeine.pdf. Accessed 22 Sept 2017

73. Lipton RB et al (1998) Efficacy and safety of acetaminophen, aspirin, and caffeine in alleviating migraine headache pain: three double-blind, randomized, placebo-controlled trials. Arch Neurol 55(2):210-217

74. Migliardi JR et al (1994) Caffeine as an analgesic adjuvant in tension headache. Clin Pharmacol Ther 56(5):576-586

75. Zhang WY (2001) A benefit-risk assessment of caffeine as an analgesic adjuvant. Drug Saf 24(15):1127-1142

76. GW, D. and C. DO, Caffeine and the lower esophageal sphincter. Am J Dig Dis, 1972. 7: p. 993-996

77. Cohen S, Booth GH Jr (1975) Gastric acid secretion and lower-esophagealsphincter pressure in response to coffee and caffeine. $\mathrm{N}$ Engl J Med 293(18):897-899

78. Eisig JN et al (1989) Coffee drinking in patients with duodenal ulcer and a control population. Scand J Gastroenterol 24(7):796-798

79. Wendl B et al (1994) Effect of decaffeination of coffee or tea on gastrooesophageal reflux. Aliment Pharmacol Ther 8(3):283-287

80. Shimamoto T et al (2013) No association of coffee consumption with gastric ulcer, duodenal ulcer, reflux esophagitis, and non-erosive reflux disease: a cross-sectional study of 8,013 healthy subjects in Japan. PLoS One 8(6):e65996

81. Michielsen P et al (2009) Non-phenacetin analgesics and analgesic nephropathy: clinical assessment of high users from a case-control study. Nephrol Dial Transplant 24(4):1253-1259

82. Feinstein AR et al (2000) Relationship between nonphenacetin combined analgesics and nephropathy: a review. Ad hoc Committee of the International Study Group on analgesics and nephropathy. Kidney Int 58(6):2259-2264

83. Lee MJ et al (2016) Caffeine discontinuation improves acute migraine treatment: a prospective clinic-based study. J Headache Pain 17(1):71

84. Bigal ME et al (2008) Acute migraine medications and evolution from episodic to chronic migraine: a longitudinal population-based study. Headache 48(8):1157-1168

85. Di W et al (2013) Overuse of paracetamol caffeine aspirin powders affects cerebral glucose metabolism in chronic migraine patients. Eur J Neurol 20(4):655-662

86. Bahra A et al (2003) Does chronic daily headache arise de novo in association with regular use of analgesics? Headache 43(3):179-190

87. Paemeleire K et al (2006) Medication-overuse headache in patients with cluster headache. Neurology 67(1):109-113

88. Wilkinson SM, Becker WJ, Heine JA (2001) Opiate use to control bowe motility may induce chronic daily headache in patients with migraine. Headache 41(3):303-309

89. Zwart JA et al (2004) Analgesic overuse among subjects with headache, neck, and low-back pain. Neurology 62(9):1540-1544

90. Dodick D, Freitag F (2006) Evidence-based understanding of medicationoveruse headache: clinical implications. Headache 46(Suppl 4):S202-S211

91. Scher Al, Stewart WF, Lipton RB (2004) Caffeine as a risk factor for chronic daily headache: a population-based study. Neurology 63(11):2022-2027

92. Scher Al et al (2010) Patterns of medication use by chronic and episodic headache sufferers in the general population: results from the frequent headache epidemiology study. Cephalalgia 30(3):321-328

93. Bendtsen $L$ et al (2010) EFNS guideline on the treatment of tension-type headache - report of an EFNS task force. Eur J Neurol 17(11):1318-1325

94. Bernstein GA et al (2002) Caffeine dependence in teenagers. Drug Alcohol Depend 66(1):1-6

95. Hughes JR, Hale KL (1998) Behavioral effects of caffeine and other methylxanthines on children. Exp Clin Psychopharmacol 6(1):87-95

96. Kozlowski LT et al (1993) Patterns of alcohol, cigarette, and caffeine and other drug use in two drug abusing populations. J Subst Abus Treat 10(2):171-179

97. $C P, O . B$. Is there an abuse potential for caffein-containing analgesic combinations?, in Advances in the management of acute pain. International Congress and Symposium Series No. 218, H. A, Editor. 2015. p. 11-15 
98. Reissig CJ, Strain EC, Griffiths RR (2009) Caffeinated energy drinks-a growing problem. Drug Alcohol Depend 99(1-3):1-10

99. M, W., K. Marquardt, and T. Albertson, Adverse effects fro ingestion of Redline Energy Drinks. Clin Toxicol, 2006. 44: p. 642

100. Iyadurai SJ, Chung SS (2007) New-onset seizures in adults: possible association with consumption of popular energy drinks. Epilepsy Behav 10(3):504-508

101. Worrall BB, Phillips CD, Henderson KK (2005) Herbal energy drinks, phenylpropanoid compounds, and cerebral vasculopathy. Neurology 65(7):1137-1138

102. Chrysant SG, Chrysant GS (2015) Cardiovascular complications from consumption of high energy drinks: recent evidence. J Hum Hypertens 29(2):71-76

103. Ferre S, O'Brien MC (2011) Alcohol and caffeine: the perfect storm. J Caffeine Res 1(3):153-162

104. Evans SM, Griffiths RR (1992) Caffeine tolerance and choice in humans. Psychopharmacology 108(1-2):51-59

105. Griffiths RR, M.G., Caffeine reinforcement, discrimination, tolerance, and physical dependence in laboratory animals and humans, in Pharmacological Aspects of Drug Dependence: Toward an Integrated Neurobehavioral Approach (Handbook of Experimental Pharmacology), S. CR and K. MJ, Editors. 1996, Springer: Berlin, Heidelberg, New York. p. 315-341

106. Robertson D et al (1981) Tolerance to the humoral and hemodynamic effects of caffeine in man. J Clin Invest 67(4):1111-1117

107. Kendler KS, Prescott CA (1999) Caffeine intake, tolerance, and withdrawal in women: a population-based twin study. Am J Psychiatry 156(2):223-228

108. Shapiro RE (2008) Caffeine and headaches. Curr Pain Headache Rep 12(4): $311-315$

109. Evans SM, Griffiths RR (1999) Caffeine withdrawal: a parametric analysis of caffeine dosing conditions. J Pharmacol Exp Ther 289(1):285-294

110. Couturier EG et al (1997) Influence of caffeine and caffeine withdrawal on headache and cerebral blood flow velocities. Cephalalgia 17(3):188-190

111. Couturier EG, Hering R, Steiner TJ (1992) Weekend attacks in migraine patients: caused by caffeine withdrawal? Cephalalgia 12(2):99-100

112. Sousa Melo E (2017) F. Carrilho Aguiar, and P.A. Sampaio Rocha-Filho, Dialysis Headache: A Narrative Review. Headache: The Journal of Head and Face Pain 57(1):161-164

113. Fennelly M, Galletly DC, Purdie GI (1991) Is caffeine withdrawal the mechanism of postoperative headache? Anesth Analg 72(4):449-453

114. Goldstein J et al (2006) Acetaminophen, aspirin, and caffeine in combination versus ibuprofen for acute migraine: results from a multicenter, double-blind, randomized, parallel-group, single-dose, placebocontrolled study. Headache 46(3):444-453

115. Pfaffenrath $V$ et al (2009) OTC analgesics in headache treatment: open-label phase vs randomized double-blind phase of a large clinical trial. Headache 49(5):638-645

116. Dooley JM et al (2007) Caffeine as an adjuvant to ibuprofen in treating childhood headaches. Pediatr Neurol 37(1):42-46

117. Yancey JR, Dattoli G (2013) Caffeine as an analgesic adjuvant for acute pain in adults. Am Fam Physician 87(1):11

\section{Submit your manuscript to a SpringerOpen ${ }^{\circ}$ journal and benefit from:}

- Convenient online submission

- Rigorous peer review

- Open access: articles freely available online

- High visibility within the field

- Retaining the copyright to your article 